\title{
Hematoma Localization under Ultrasound-Guidance for Excision (HUGE) of Impalpable Breast Lesions, a Modification to make Screening Effective in Nigeria: Pilot study
}

\author{
Article by Agodirin SO ${ }^{1,2}$, Olatoke $\mathrm{SA}^{2}$, Rahman $\mathrm{GA}^{2}$, Akande $\mathrm{HJ}^{3}$, Habeeb OG ${ }^{2}$ \\ ${ }^{1}$ School of clinical research, Texila American University, Guyana, South America \\ ${ }^{2}$ Department of Surgery University of Ilorin Teaching Hospital \\ ${ }^{3}$ Department of Radiology University of Ilorin Teaching Hospital \\ Email: Cancer1992@yahoo.com ${ }^{1}$
}

\begin{abstract}
Background: Diagnosing and treating impalpable breast lesions is one of the greatest gains of screening and it is a game changer in winning against breast cancer. Screening must be complemented with availability of methods to handle impalpable lesions. At the least, impact of screening is considerably diminished and at worst, screening will be counterproductive or downright unethical if detected lesions cannot be diagnosed and treated, yet standard methods of handling impalpable lesions are not available or not sustainable in lowincome centers.

Objective: To make screening effective by finding cheap and sustainable method of localizing, diagnosing and treating impalpable breast lesions.

Method: Intra-operative ultrasound (USS) directed biopsy of impalpable breast lesions was modified so that the localization and operative procedure can be dissociated and performed with limited facility; Under USS-guidance at the radiology department, hematoma was formed around impalpable lesions by injecting 3-4mls of patient's own blood into them and incision placement was planned at the same time. Two to 3 days later, during open surgical procedure without intra operative USS-facility, the iatrogenic hematomas were found and excised. Primary measures of outcome were achievement of successful excision and histological diagnosis.

Result: Following walk-in screening, 5impalpable breast lesions visible to mammography and ultrasound were included. All 5 were successfully localized and excised. Histological diagnosis was reached in all 5 lesions.

Conclusion: This small volume pilot experience demonstrated how impalpable lesions can be handled in poor resource centers. The HUGE method allows flexibility of scheduling and lowers dependence on high technology.
\end{abstract}

Keywords: Hematoma localization, Impalpable, breast lesion, low-income

\section{Background}

Modern surgical practice of breast cancer management is witnessing detection and diagnosis of majority of lesions when they are still impalpable (1-3). The gains of diagnosing impalpable lesions includes reduction in the cost of treatment, availability of wider array of surgical treatment, minimization of trauma of treatment and remarkable increment in the chances of cure. These are incentives which will make orthodox care attractive.

Diagnosis and treatment of impalpable breast lesion is one of the major factors revolutionizing the outcome of breast cancer treatment in developed centers because of high rate of screening backed by facilities for excision of impalpable lesions such as wire localization biopsies, ultrasound guided biopsies, and various tissue marking guided biopsies(1-7).

In contrast, centers in developing countries are deficient in the capability to detect, localize, diagnose or treat impalpable lesions(8). The unfortunate implication of not possessing the capability to handle impalpable lesion(s) is having to wait until the lesions are 
Texila International Journal of Medicine

Volume 4, Issue 2, Dec 2016

clinically palpable, at which time the treatment becomes more difficult, more expensive, more mutilating and unattractive to patients(8) thus fueling vicious cycle of late presentation (912).

It is imperative that we find and demonstrate acceptable and attractive treatment options in order to reverse the trend of late presentation in developing centers(13). In addition to helping to tackle the poor trend of management outcomes, presence of effective and acceptable treatment options is a prerequisite before rolling out screening programs.

Therefore, a pilot research was designed with the goal of finding a relatively cheap and sustainable method of localization, diagnosis and treatment of impalpable breast lesions in a resource poor center. Success in our quest will make screening more effective and orthodox care more appealing. This article is a report of our experience in the pilot research; Hematoma localization under Ultrasound Guidance for Excision (HUGE) of impalpable breast lesions, a modification of hematoma directed ultrasound guided biopsy.

\section{Setting and method}

This pilot research was conducted in General surgery II division, department of Surgery and Radiology department of the University of Ilorin teaching Hospital, Ilorin Nigeria after satisfying ethical requirements.

Following walk-in breast screening using sonography (USS) and/or mammography (mammo), impalpable but sonographically detectable lesions adjudged to be suspicious were included in the research if diagnosis could not be reached by USS-guided fine needle biopsy(FNB). Patients whose lesions were palpable or whose diagnosis could be reached by FNB were excluded. Pregnant and lactating females were also excluded. One patient whose BI-RADS score was not suspicious but who had a family history of carcinoma of the breast in two siblings and one parent was included because she preferred excision of the lesion and to have a pathologic diagnosis rather than reassurance of sonographic score.

\section{Preoperative hematoma localization under sonographic guidance}

This was carried out in the radiology department with the surgeon in attendance 2-3 days before the proposed day of surgical excision. This flexibility of localization day fitted with the schedule of the sinologists (USS day) and the surgeon (surgical outpatient clinic day). The USS machine used was SONOACE X4 with probe frequency 7.5MHz. After US localization of the lesion, in terms of location in the breast when the areola was likened to the face of a clock, depth from the skin and distance from the areola, 3-4 mls of patient's own venous blood was injected into and around the lesion using the hollow trocar of an 18G intravenous cannula. The point of insertion was cleansed with alcohol and numbed with lidocaine injection. Antiseptic lotion was used to reduce contamination and as an acoustic coupling agent. Prophylactic antibiotics were not given.

\section{Surgical localization and excision technique}

All excisions were performed under local anesthesia with adrenaline containing lidocaine injection. A transverse directly overlying skin incision was placed based on the prior planning during the sonographic localization 2-3days earlier. After making appropriate length incision on the skin, 2-3 cm of skin flap was raised in all directions, subcutaneous layer and superficial breast parenchyma was parted or cleared (figure1) after sagittal and cruxiate incisions were made to access the deeper tissue and visualize the area of hematoma formation. The identified hematoma was completely excised with a rim of normal tissue (figure2). The specimen was tagged for appropriate orientation and sent for histology.

Attempt was made to reconstruct the normal contour of the breast by local tissue advancement flap. Hemostasis was secured, the skin was close with nylon 2/0 interrupted mattress suturing and firm bandaging was applied for 3days. All cases were performed as day case, none of the patients had prophylactic antibiotic and drains were not inserted in any of 
the patients. The wounds were inspected on day 3, sutures were removed on $10^{\text {th }}$ postoperative day

Measures of Outcome. The primary measures of outcome was "yes" or "no" response to whether the surgeon was able to find and excise the hematoma (lesion) without USS-guidance and whether histologic diagnosis was reached. The occurrence of postoperative complications was secondary measure of outcome

\section{Results}

Between July 2014 and August 2016, 5 patients fit the inclusion criteria. The age range was 38-53. Four lesions were on the left while one was on the right. Excision was successful in all cases. Histologic diagnosis was reached in all cases and excision was therapeutic in all cases. Early postoperative complications ensued in 4 of the 5 patients, one had late complication (mild distortion of the areola). None of the lesions was malignant. (table 1)

Table1

\begin{tabular}{|c|c|c|c|c|c|}
\hline Age & Side & location & Clinical comments & histology & $\begin{array}{l}\text { Postoperative } \\
\text { complications }\end{array}$ \\
\hline 38 & Right & central & $\begin{array}{l}\text { ?Genetic predisposition; } \\
\text { Mother and one sibling } \\
\text { died of CAB } \\
\text { Living sibling } \\
\text { diagnosed of CAB } \\
\text { Ultrasound detected } \\
\text { lesion } \\
\text { BI-RADS III (excision } \\
\text { preferred) }\end{array}$ & $\begin{array}{l}\text { Fibrocystic } \\
\text { changes }\end{array}$ & $\begin{array}{l}\text { SSI } \\
\text { Wound } \\
\text { dehiscence } \\
\text { Mild distortion }\end{array}$ \\
\hline 50 & left & UOQ & $\begin{array}{l}\text { Blood discharge } \\
\text { Mammographic } \\
\text { calcifications } \\
\text { Architectural distortion } \\
\text { BI-RADS IV } \\
\end{array}$ & $\begin{array}{l}\text { Intra-ductal } \\
\text { papilloma } \\
\text { Fibrocystic } \\
\text { changes }\end{array}$ & Nil \\
\hline 53 & left & UOQ & $\begin{array}{l}\text { BIRAD IV } \\
\text { Excision advised }\end{array}$ & Fat necrosis & $\begin{array}{l}\text { SSI } \\
\text { Wound } \\
\text { dehiscence }\end{array}$ \\
\hline 49 & left & UOQ & $\begin{array}{l}\text { BI-RADS IV } \\
\text { Excision advised }\end{array}$ & $\begin{array}{l}\text { Fibrocystic } \\
\text { changes }\end{array}$ & SSI \\
\hline 43 & left & UOQ & $\begin{array}{l}\text { BI-RADS IV } \\
\text { Excision advised }\end{array}$ & $\begin{array}{lr}\text { Breast cyst lined } \\
\text { with chronic } \\
\text { inflammatory cells }\end{array}$ & Bruising \\
\hline
\end{tabular}

$\mathrm{CAB}=$ Carcinoma of the breast 
Texila International Journal of Medicine

Volume 4, Issue 2, Dec 2016

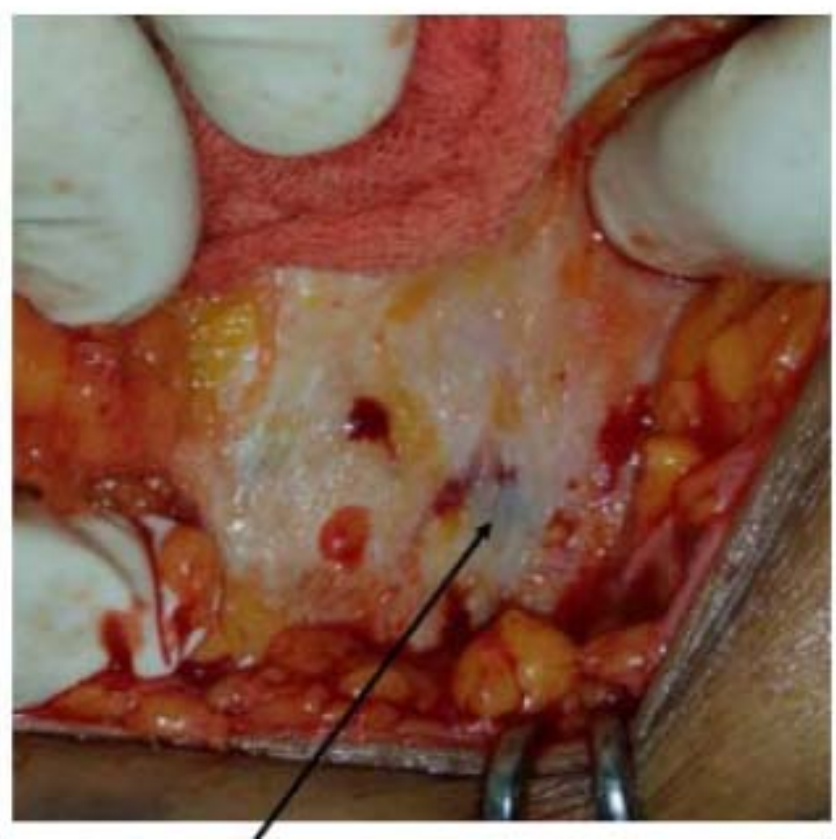

Figure1

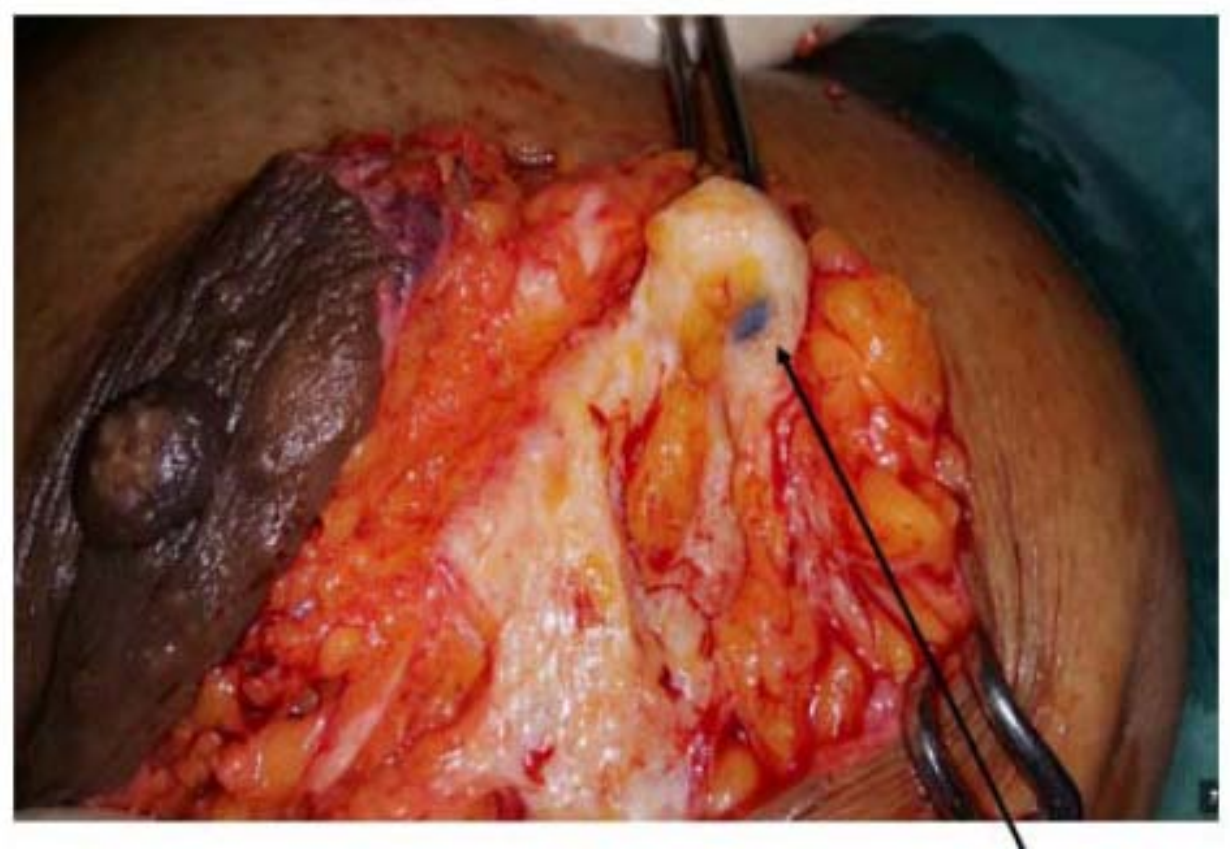

Figure 2

\section{Discussion}

Screening to diagnose and treat impalpable lesions is a game changer in winning against breast cancer. Screening should be complemented with ability to diagnose and treat detected lesions. At the least, the impact of screening is diminished and at the worst, screening will be counter-productive or downright unethical if detected lesions cannot be correctly diagnosed and treated. Sensitive screening will increase diagnosis of suspicious and impalpable lesions and create the need to localize them for planned surgical removal. The need to find means of handling impalpable lesions combined with the goal of achieving breast conservation to complement screening in low in-come centers necessitated this study.

Wire localized biopsy is the gold standard for handling impalpable lesions, other methods of handling impalpable lesions are ultrasound directed biopsies and use of various tissue 
staining techniques. The standard methods which require sophisticated facilities and tight coordination of multiple specialists are not yet achievable nor sustainable in most resource poor centers. Previously documented less demanding techniques of excising impalpable lesions which can be implemented in developing centers include the use of methylene blue and the use of charcoal suspension (5). Both methods do not require intraoperative ultrasound. The methylene blue method still relies on a rather tight schedule while the charcoal suspension gives a lot of room (5). Both methods have the advantage of leading a trail to the lesion in contrast to the active search described for HUGE in this study, but both staining methods will not unmask the location of impalpable mammographically detected lesion(s) to sonography.

Advances in the USS techniques should be priority in resource poor countries where mammography, MRI and stereotactic procedures are not readily available. The increased utility of breast conserving surgery as fallout of these small facets of advancement in developing centers will aid acceptance of orthodox treatment. However, concern remains over the specificity of patient selection and risk of over treatment as was demonstrated in this study. Capacity building and researches centering on correlation between clinical, radiologic and pathologic features should reduce risks of these concerns. Nonetheless, we should note that over-diagnosis/over-treatment are forced compromises and are challenges in the management of impalpable breast lesions in many places where mammographic screening take center stage $(7,14)$

In this study, impalpable breast lesions were excised from the breasts of 5 women. four of the lesions had BI-RADS IV score by mammo and USS assessment, one of the lesions scored BI-RADS III but had a strong family history of breast cancer and wished to have pathologic diagnosis. All excised lesions were benign on histology. The HUGE method was successful in non-technologically aided surgical excision of the impalpable lesions. Pathologic definitive diagnosis was reached in all cases and excision was therapeutic in all cases. There is however a need to improve specificity of patient selection. The complication rate in this study was high, this is likely to improve on the learning curve and with addition of adjuncts such as prophylactic antibiotics.

In this pilot study, the volume of patients used was small. This was because of our stringent selection criteria and the underutilization of screening facilities by the populace. One other demerit of the technique is that it was a relatively blind. Even though the hematomas were formed in and around the lesions and were completely excised with rim of normal tissue, there was no immediate confirmation of complete excision.

An invaluable merit we identified is the decentralization or dissociation of the process. The flexibility whereby localization can be concluded at a separate time and in a separate space and then excision can be completed at another time and space with allowance of 2-3 days interval addresses the problem of limited time allowable on the limited space and facility. This makes it easier to achieve multidisciplinary care without clash of schedules and without owning the space, facility or expertise. This is a significant advantage over the requirements of wire localized biopsy we reported in Nigeria previously (15). In the later, after wire localization, the excision must be immediately performed and the radiologist will be on standby for immediate repeat mammography to confirm excision.

Although this was a pilot study of an evolving method, there are areas of prospect. The immediately foreseeable prospect it holds is possibility of unmasking mammographically detectable but sonographically undetectable lesions. In this scenario, a small unmaskinghematoma may be created stereotactically (at mammography), the small hematoma will reveal the location of the lesion to sonography and then the HUGE process can proceed on the unmasking-hematoma.

The cause of poor outcome of breast cancer management in developing centres is hydraheaded. However, a major contributory factor is aversion for mastectomy $(12,16)$. Hence, locally sustainable methods which promote less mutilating surgical intervention will 
Texila International Journal of Medicine

Volume 4, Issue 2, Dec 2016

undoubtedly support the necessary changes required to improve the outcome of care in developing centers.

\section{Conclusion}

This small volume pilot experience demonstrated how impalpable lesions can be detected, localized, diagnosed and treated in poor resource centers. The HUGE method uncouples the process so that flexibility is possible in scheduling and intraoperative high technologic facilities are not absolute requirements.

\section{References}

[1]. Adamczyk B, Murawa P. Preoperative localization of nonpalpable breast nodules-which method to choose? Reports of Practical Oncology and Radiotherapy. 2008:201-4.

[2]. Ahmad S, Ginawi AE, Sabbagh S. DEDICATED BREAST CANCER MANAGEMENT CENTRES WITH. FACILITIES FOR FULL IMAGE-GUIDED ASSESSMENT AND IMAGEGUIDED SURGERY IN THE DEVELOPING AREAS OF PAKISTAN--A LONG OVERDUE NECESSITY. Journal of Ayub Medical College, Abbottabad : JAMC. 2015;27(1):251-4.

[3]. Agodirin O, Olatoke S, Rahman G, Adeoti M, Oyeyemi G, Durojaiye A, et al. How effective is the treatment of locally advanced and metastatic breast cancer in Developing centers; A retrospective review Ethiop J Health Sci. 2015;25(4):338-44.

[4]. Anyanwu SN, Egwuonwu OA, Ihekwoaba EC. Acceptance and adherence to treatment among breast cancer patients in Eastern Nigeria. Breast. 2011;20 Suppl 2:S51-3.

[5]. Alikhassi A, Ahmadinejad N, Sedighi N, Najafi M. Stereotactic breast core needlel biopsy in a tertiary breast center of tehran University of Medical sciences Arch Breast Cancer. 2015;2 (1):21-6.

[6]. Agodirin SO, Ojemakinde OM, Bello TO, Oguntola AS, Aremu AA, Ojemakinde KO, et al. Ultrasound-guided wire localization of lesions detected on screening mammography in Osogbo, Nigeria and its impact on breast conservative surgery. Ann Afr Med. 2012;11(2):91-5.

[7]. Akanbi oO, A. Adeoti, M. Aderounmu, A. Idris, O. Abayomi, O. Delay presentation of breast cancer: A study among south western Nigerian women. International Journal of Current Research. 2015;7.

[8]. Blumencranz PW, Ellis D, Barlowe K. Use of hydrogel breast biopsy tissue markers reduces the need for wire localization. Ann Surg Oncol. 2014;21(10):3273-7.

[9]. Chan BK, Wiseberg-Firtell JA, Jois RH, Jensen K, Audisio RA. Localization techniques for guided surgical excision of non-palpable breast lesions. The Cochrane database of systematic reviews. 2015 (12):Cd009206.

[10]. Egwuonwu O, Anyanwu S, Ihekwoaba E, Chianakwana G, Iloabachie I. Pattern of presentation and adherence to treatment in young breast cancer patients Orient Journal of Medicine. 2013;25 (12):14-8.

[11]. Ko K, Han BK, Jang KM, Choe YH, Shin JH, Yang JH, et al. The value of ultrasound-guided tattooing localization of nonpalpable breast lesions. Korean Journal of Radiology. 2007; 8 (4):295-301.

[12]. Mascaro A, Farina M, Gigli R, Vitelli CE, Fortunato L. Recent advances in the surgical care of breast cancer patients. World J Surg Oncol. 2010;8:5.

[13]. Memon MA, Berstock DA. Ultrasound-guided excision of impalpable mass breast lesion. Annals of The Royal College of Surgeons of England. 1996;78 (1):61-2.

[14]. Masroor I, Afzal S, Shafqat G, Rehman H. Usefulness of hook wire localization biopsy under imaging guidance for nonpalpable breast lesions detected radiologically. International Journal of Women's Health. 2012;4:445-9.

[15]. Ogundiran TO, Ayandipo OO, Ademola AF, Adebamowo CA. Mastectomy for management of breast cancer in Ibadan, Nigeria. BMC Surgery. 2013;13:59.

[16]. Sule E. Breast conservation for T3/T4 Tumors in a developing country. wjpmr. 2016;2 (4):39-42. 